\title{
Megaeventos esportivos no Brasil: De expressão da política esportiva brasileira para a da concepção neodesenvolvimentista de planejamento urbano*
}

\author{
Lino Castellani Filho** \\ Recibido: septiembre 9 de 2014 • Evaluado: octubre 20 de 2014
}

Aceptado: noviembre 11 de 2014

Resumo

Buscamos neste Ensaio tecer considerações acerca dos megaeventos esportivos em solo brasileiro como expressão maior de uma determinada lógica de desenvolvimento urbano e menos de uma política esportiva propriamente dita, atentando para seus impactos na América do Sul. Neste particular, focaremos o paradoxo presente entorno do discurso oficial centrado no reconhecimento do Esporte como Direito Social versus uma prática comprometida com a concepção neodesenvolvimentista de planejamento urbano, ratificadora de sua apreensão como produto passível de ser mercantilizado com alto apelo no campo dos negócios.

Palavras-chave: megaeventos esportivos, copa FIFA 2014, movimentos sociais, controle social, planejamento urbano.

"O Artigo em pauta reflete estudos desenvolvidos junto ao "Grupo de Estudos e Pesquisas de Políticas de Educação Física, Esporte e Lazer - Observatório do Esporte” (www.observatoriodoesporte.org.br) -, integrante do Diretório de Grupos do Conselho Nacional de Pesquisa do Ministério de Ciência \& Tecnologia do Brasil, do qual seu autor é "Pesquisador-líder".

"* Doutor em Educação (Unicamp). Pesquisador-líder do Observatório de Políticas de Educação Física, Esporte e Lazer - Observatório do Esporte (CNPq-Unicamp). Professor LivreDocente (aposentado) da Unicamp; Professor-Visitante da Universidade de Brasília (UnB 2012/13) Secretário Nacional - Secretária Nacional de Desenvolvimento do Esporte e Lazer do Ministério do Esporte (2003/06). Presidente do Colégio Brasileiro de Ciências do Esporte, CBCE (1999/03). Endereço Eletrônico: lino@fef.unicamp.br 


\section{Megaeventos deportivos en Brasil: de expresión de la política deportiva brasileña para la concepción neodesarrollista de planeamiento urbano}

\section{Resumen}

Buscamos en este ensayo tejer consideraciones acerca de los megaeventos deportivos en suelo brasileño como expresión mayor de una determinada lógica de desarrollo urbano y menos de una política deportiva propiamente dicha, fijando para sus impactos en América del sur. Sobre este particular enfocaremos la paradoja presente entorno del discurso oficial centrado en el deporte como derecho social versus una práctica comprometida con la concepción neodesarrollista de planeamiento urbano, ratificadora de su aprensión como producto susceptible de ser mercantilizado con alto atractivo en el campo de los negocios.

Palabras clave: megaeventos deportivos, copa FIFA 2014, movimientos sociales, control social, planeamiento urbano. 


\title{
Mega sporting events in Brazil: the expression of Brazilian sports policy for the neo-developmentalism urban planning conception
}

\begin{abstract}
We seek in this essay to weave considerations about mega sporting events on Brazilian soil as a greater expression of a certain logic of urban development and less of a sports policy itself, setting for their impacts in South America. On this particular we will focus the existing paradox around the official speech focused on sports as a social right versus a practice committed with the neo-developmentalist conception of urban planning, ratifying of its apprehension as product capable of being commercialized with high attraction in the field of business.
\end{abstract}

Keywords: mega sporting events, FIFA 2014, social movements, social control, urban planning. 


\section{A respeito de nossa intenção}

Tendo como horizonte as mobilizações sociais havidas a partir de junho de 2013 no Brasil e da máxima Gramsciana defensora do par dialético "pessimismo da razão, otimismo da vontade", buscamos neste Ensaio tecer considerações acerca dos megaeventos esportivos em solo brasileiro como expressão maior de uma determinada lógica de desenvolvimento urbano e menos de uma política esportiva propriamente dita, atentando para seus impactos na América do Sul ${ }^{1}$.

Neste particular, focaremos o paradoxo presente entorno do discurso oficial centrado no reconhecimento do Esporte como Direito Social versus uma prática comprometida com a concepção neodesenvolvimentista ${ }^{2}$ de planejamento urbano, ratificadora de sua apreensão como produto passível de ser mercantilizado com alto apelo no campo dos negócios.

Tal ação no âmbito da esfera pública é responsável pela configuração de lógica política inibidora - por não cabível naquela concepção - da mediação da sociedade civil organizada, de matiz progressista, nas relações entre Governo e empresariado, dando vazão à perspectiva de gestão das cidades em desacordo com o estabelecido em seus

1 Nesse particular mais do que "dialogar" com a realidade dos países sul-americanos, desejamos chamar a atenção dos mesmos para o fato de que os acontecimentos presentes em nosso país - reconhecendo a importância geopolítica brasileira -, motivados pela organização dos megaeventos (esportivos ou não), transcendem os limites territoriais brasileiros e se coadunam com uma concepção de planejamento e desenvolvimento urbano própria à forma liberal - em sua expressão máxima, o neoliberalismo-"desenhada" no primeiro mundo e imposta àqueles subdesenvolvidos. Por sua vez, busca dar continuidade à interlocução que vimos construindo há tempos com acadêmicos do campo da Educação Física de países de nossa sulamérica.

2 Armando Boito Júnior em trabalho apresentado na edição de 2012 do Fórum Econômico da FGV/São Paulo, denominado - As bases políticas do neodesenvolvimentismo- traduz o neodesenvolvimentismo como uma "frente política (de) base ampla e heterogênea de sustentação da política de crescimento econômico e de transferência de renda encetadas pelos governos Lula da Silva e Dilma Rousseff". Ainda para ele, caracteriza-se como "um programa de política econômica e social que busca o crescimento econômico do capitalismo brasileiro com alguma transferência de renda, embora o faça sem romper com os limites dados pelo modelo econômico neoliberal ainda vigente no país”. Seria, ainda segundo suas palavras, -O desenvolvimentismo da época do capitalismo neoliberal-. Disponível em: http://eesp.fgv. br/sites/eesp.fgv.br/files/file/Painel\%203\%20-\%20Novo $\% 20$ Desenv $\% 20$ BR $\% 20-\% 20$ Boito $\% 20$ -\%20Bases\%20Pol\%20Neodesenv\%20-\%20PAPER.pdf 
Planos Diretores ${ }^{3}$, caracterizando o quadro denominado - nas palavras do urbanista da

Universidade Federal do Rio de Janeiro, Carlos Vainer -, de -"Cidades -de-Exceção"4.

É neste contexto que os megaeventos esportivos se apresentam como artífices da referida lógica, fazendo com que a política esportiva a ela se subordinasse de forma consentida - tanto por vê-la conciliada aos interesses do setor conservador (e hegemônico) do campo esportivo brasileiro, quanto pela necessidade de legitimação junto ao campo esportivo (no mais puro sentido de campo empregado por Bourdieu) - por parte dos responsáveis pela política governamental na referida área ${ }^{5}$.

Assim, i) sociedade civil organizada em movimentos sociais refratários à realização dos referidos megaeventos esportivos, dada a existência de prioridades de apelo social mais premente, além da lógica organizativa deles, nefasta aos setores menos favorecidos da sociedade brasileira; ii) setores privados sem fins lucrativos (conhecidos, dentre outras formas, como Organizações NãoGovernamentais, ONGs) responsáveis pela desresponsabilização do Estado de suas atribuições redistributivas, além da filantropização das políticas sociais; e III) iniciativas governamentais falseadoras da participação popular nas ações de elaboração, execução e fiscalização das políticas esportivas - tais como a

3 Os chamados Planos Diretores estabelecem parâmetros para o planejamento urbano dos municípios brasileiros. A exigência de sua elaboração está presente na lei n ${ }^{\circ} 10257 / 01$, conhecida como Estatuto da Cidade, que regulamenta artigos da Constituição brasileira atinentes à Política Urbana. Disponível no endereço http://www.ifrc.org/docs/idrl/947PT.pdf

4 De acordo com Carlos Vainer, "Cidade de exceção: reflexões a partir do Rio de Janeiro", In: XIV ENCONTRO NACIONAL DA ANPUR, 2011, p. 10), a "Cidade de Exceção se afirma como uma forma nova de regime urbano (que) não obstante o funcionamento dos mecanismos e instituições típicas da república democrática representativa, os aparatos institucionais formais progressivamente abdicam de parcela de suas atribuições e poderes. A lei torna-se passível de desrespeito legal e parcelas crescentes de funções públicas do Estado são transferidas a agências "livres de burocracia e controle político". Em outras palavras estamos diante de uma nova modalidade de planejamento urbano, surgida nos anos 1980, na qual as regras de organização do espaço urbano devem ser subordinadas à lógica do negócio". Disponível em http://www.opp.ufc.br/urbano04. pdf Acesso em: 06 mar. 2014.

5 Em relação a essa busca de legitimação, sugerimos a leitura do ensaio "O PT, a política esportiva brasileira e a Síndrome de Estocolmo" In: -Educação Física, esporte e lazer: reflexões nada aleatórias" (Campinas: Autores Associados, 2013). p. 62-66. 
Conferência Nacional de Esporte $e^{6}$ se apresentou —, são tratadas sem perder de vista a maneira como a mídia em geral e a especializada, em particular, vem dando ressonância de seus sentidos e significados na formatação da opinião pública.

\section{A pouco tempo de muita coisa}

Escrevemos em 2014, a poucos dias do "aniversario" de 50 anos do golpe civil-militar que assolou a sociedade brasileira em $1^{\circ}$ de abril de 1964 . Não obstante, o fervilhar social ora presente em terras brasileiras guarda menos relação com o episódio que por 20 anos perdurou entre nós, com sérias e visíveis sequelas para a nossa ainda jovem democracia, do que com o incômodo causado em setores médios e populares de nossa sociedade pelo processo organizativo da Copa FIFA $2014^{7}$ em nossas terras, alimentando nesses setores o sentimento de que demandas sociais tidas como prioritárias pelos segmentos sociais mencionados (transporte público, saúde, educação...) foram relegadas a um segundo plano pelas hostes governamentais. Sentimento justo, ora apropriado por setores políticos de oposição com olhares voltados ao processo eleitoral de outubro vindouro, que coloca em jogo a presidência do país e a governança dos Estados brasileiros, além das cadeiras dos legislativos federal e estaduais.

É verdade que o Estado Nacional brasileiro se enquadra nos padrões adotados pela lógica neoliberal, traduzida de forma singela pelo renomado geógrafo Milton Santos ao dizer que: "se fala, com insistência, na morte do Estado, mas o que estamos vendo é seu fortalecimento para atender os reclamos do setor financeiro e outros grandes interesses internacionais, em detrimento dos cuidados com as populações, cujas vidas se tornam mais difíceis”.

6 Sobre o assunto indicamos a leitura do ensaio - III CONFERÊNCIA NACIONAL DE ESPORTE: risco de engodo e empulhação-In: -Educação Física, esporte e lazer: reflexões nada aleatórias" (Campinas: Autores Associados, 2013). p. 66-70.

7 Me reporto a megaeventos - trazendo especificidades da Copa FIFA 2014 - por entender que a lógica de desenvolvimento urbano que nela, Copa, se faz presente, transcende o referido evento abarcando todos os demais rotulados como megaeventos, para além dos "esportivos", inclusive. Por esta razão optamos, inclusive, por manter a expressão no título deste Ensaio.

8 Conforme Milton Santos, "Por uma outra globalização: do pensamento único à consciência universal”. 6. ed. Rio de Janeiro: Graal, 2001. p. 19 
Contudo, suas nuances - aqui já mencionadas quando nos referimos ao conceito de neodesenvolvimentismo - nos revelam ser ele responsável pelo resgate do nível de 0,530 de desigualdade na escala Gini/2012, apurado pelo Ipea (Instituto de Pesquisa Econômica Aplicada) - algo próximo de uma sociedade mais equilibrada, resultado de políticas distributivas de renda, de combate à inflação e de ampliação dos postos formais no mercado de trabalho -, índice só encontrado no início da década de 1960, antes do golpe civil-militar, tomando por base os censos de 1960 e 1970.

É o que se depreende do artigo publicado no jornal "Valor Econômico" escrito por Maria Clara R, M. Prado". Ainda segundo a autora da matéria, “(...) em 'De volta ao país do futuro' Marcelo Neri, ministro da Secretaria de Assuntos Especiais e coordenador do livro, mostra que o índice Gini passou de 0,5367 em 1960 para 0,5828 em 1970, considerando os dados levantados na época pelo economista Carlos Geraldo Langoni, da FGV”. Diz ainda Maria Clara que os dados do Ipea "revelam que o índice Gini manteve-se elevado durante os anos 80, chegando ao seu pior resultado - na marca de 0,636 - em 1989, último ano do governo Sarney, já na era da democracia”.

Mas nada disso foi levado em conta nos movimentos deflagrados a partir de junho de 2013. Diferentemente de seus predecessores, chamaram a atenção pelo fato de serem - pelo menos aparentemente - acéfalos, vale dizer, com foco claro, mas sem direção política, trazendo como resultado a ausência de saldo organizativo.

Convocados pelas mais distintas redes sociais, tiveram como característica a total rejeição à presença das bandeiras dos partidos políticos, mesmo daqueles situados à esquerda do espectro político partidário brasileiro, aliada a um sentimento de descrença da classe política motivado pelo entendimento generalizado acerca do alto nível de corrupção que os assola, explicitando uma preocupante descrença das instituições representativas da ordem democrática.

A maioria esclarecida foi pega de surpresa pelos acontecimentos, ressalvados alguns intelectuais de militância política e acadêmica situados no universo da esquerda do campo político brasileiro e sul-americano. Destaca-se dentre eles o professor Mauro Iasi, professor adjunto da Escola de

9 Conforme Maria Clara R. M. Prado, “Renda, de volta a 1964”. In: "Valor Econômico”, versão digital, 20 fev. 2014. 
Serviço Social da UFRJ, presidente da ADUFRJ, pesquisador do NEPEM (Núcleo de Estudos e Pesquisas Marxistas), do NEP 13 de Maio e membro do Comitê Central do PCB. Diz ele em pertinente artigo ${ }^{10}$ : "se há algo que é muito conhecido para quem não se limita ao presentismo - ou, foucaultianamente, à álea singular do acontecimento - é a insurreição, a explosão de massas”.

Com ironia, segue ele:

"Caso tenham preconceitos contra nossa tradição marxista e se recusem a ler as brilhantes análises de Lênin em 'Os ensinamentos da insurreição de Moscou', ou de Trotski em 'A arte da insurreição', podem se remeter aos estudos de Freud em 'A psicologia de massas e análise do eu', ou a magistral análise de Sartre em 'A critica da razão dialética'”.

“As massas explodem em uma dinâmica que altera profundamente o comportamento dos indivíduos isolados que pacificamente se dirigiam diariamente ao matadouro do capital, em ordem, pacificamente, saindo de suas casas humildes, pegando ônibus superlotados e precários, sendo humilhados pela polícia, vivendo de seus pequenos salários, vendo a orgia ostensiva do consumo e tendo que - subviver - com o que não tem".

Seguimos com ele falando das manifestações no Brasil:

"Em primeiro lugar as manifestações expressam um descontentamento que germinava e que era alimentado pela ação que queria negá-lo, isto é, pela arrogância de um discurso oficial que insistia em afirmar que tudo ia bem: a economia estava bem, não porque garantia a produção e reprodução da vida, mas porque permitia a reprodução do capital com taxas de lucros aceitáveis, o Brasil escapara do pior da crise internacional a golpes de pesados subsídios às empresas monopolistas, a inflação estava "dentro da meta", o Brasil recebia eventos esportivos e se transformava em um canteiro de obras, os trabalhadores apassivados e suas entidades amortecidas pelo transformismo

10 "Pode ser a gota d'água: enfrentar a direita avançando a luta socialista". Publicado em 26 jun. 2013 no blog da Boitempo (http://blogdaboitempo.com.br/2013/06/26/pode-sera-gota-dagua-enfrentar-a- direita-avancando-a-luta-socialista/). No mesmo endereço pode ser acessado vídeo no qual as manifestações são vistas e por ele "passadas a limpo". Também nele é possível acessar reflexões de outros cientistas sociais. Por sua vez, lançamos mão neste texto de citações tidas como longas no/pelo meio acadêmico, por demais aprisionado pelos "formalismos" que o caracteriza. Justifico-as pela estratégia de estabelecer nexos entre elas e o pensamento deste autor, na busca de um resultado de cunho original. 
e pela democracia de cooptação se rendiam ao consumo via endividamento, o governo se regozijava com índices de aceitação que pareciam sólidos”.

Ainda com ele:

A explosão (popular) é perfeitamente compreensível como forma de manifestação de um profundo descontentamento, (mas) sabemos que é mais do que isto. Representa, também, o esgotamento de uma forma que tem sido muito eficaz de domínio e controle político. Cultivamos um fetiche pela forma democrática como se ela em si mesmo fosse a solução enfim encontrada pela humanidade para superar um dilema histórico da ordem burguesa que a acompanha desde o nascimento e que não tem solução dentro da sociedade capitalista: o abismo entre sociedade e Estado.

Também o sociólogo argentino de nascença e latino-americano por convicção, diretor do Programa Latino-americano de Educação à Distância em Ciências Sociais, em Buenos Aires, Atílio A. Boron, em artigo intitulado —Brasil: Um novo ciclo de lutas populares? - ${ }^{11}$ se manifesta sobre o assunto:

-As grandes manifestações populares de protesto no Brasil derrubaram, na prática, uma premissa cultivada pela direita e assumida também por diversas organizações de esquerda - começando pelo PT e permanecendo com seus aliados: caso fosse garantido — pão e circo- ao povo - desorganizado, despolitizado, decepcionado com dez anos de governo petista - este aceitaria mansamente que a aliança entre as velhas e as novas oligarquias prosseguisse governando sem maiores sobressaltos-.

Seguimos com ele:

-... A continuidade e eficácia do programa — Bolsa Família- assegurava o pão. A Copa do Mundo e seu prelúdio, a Copa das Confederações, e depois os Jogos Olímpicos, garantiriam o circo necessário para consolidar a passividade política dos brasileiros. Esta visão, não só equivocada como profundamente reacionária (e quase sempre racista) ficou destruída nestes dias, o que revela a curta memória histórica e o perigoso autismo da classe dominante e seus representantes políticos ao esquecerem que o povo brasileiro soube ser protagonista de grandes jornadas de luta e que seus períodos

11 Disponível em:<http://www.atilioboron.com.ar/2013/06/brasil-un-nuevo-ciclo-de-luchas. html>, publicado em 25 jun. 2013. 
de apatia e passividade alternaram com episódios de súbita mobilização, que ultrapassaram os estreitos marcos oligárquicos de um estado apenas superficialmente democrático...-

Interessante realçar que as criticas à esquerda se encontraram - embora por motivações políticas distintas - com as formuladas por aquelas situadas à direita, como, por exemplo, podemos atestar na reação de jornalistas da mídia conservadora brasileira face aos movimentos em questão. Causou espécie, inclusive na mídia televisiva argentina, o papel desempenhado por um muito conhecido entre nós brasileiros: Arnaldo Jabor, da TV Globo ${ }^{12}$. Em um espaço de tempo de 72 horas, mudou camaleonicamente sua posição a respeito das mobilizações, sendo motivo de chacota tanto no Brasil quanto na Argentina. Primeiramente diz estarmos assistindo a um movimento por ele caracterizado como "burrice misturado a um rancor sem rumo". Fazendo expressão raivosa, pergunta retoricamente: —Se vingam de que?" E de forma indisfarçada explicita o alvo de seu próprio rancor:

-Esses caras vivem do passado de uma ilusão. São a caricatura violenta da caricatura de um socialismo dos anos 1950 que a velha esquerda ainda defende aqui...-. E fazendo alusão ao valor do aumento da tarifa do transporte público, mote que deu início às mobilizações de junho de 2013, exclama: -Realmente esses revoltosos de classe média não valem 20 centavos!-.

Aproximadamente três dias após a aparição acima descrita, retorna ele à TV e ao assunto, agora com entendimento cinicamente oposto ao manifestado anteriormente, com clara intenção de atacar o governo Dilma:

-À primeira vista este movimento pareceu uma pequena provocação inútil, que muitos criticaram, inclusive eu...-.

E vai em frente:

-De repente reapareceu o povo... De repente o Brasil virou um mar... Uma juventude que estava calada desde 1992 (...) acordou... Abriu os olhos e viram (sic) que temos democracia, mas uma república inoperante (...) paralisada por interesses partidários e privados...-

12 Disponívelem<http://www.youtube.com/watch?feature=player_embedded\&v=aS7LmKld_ $m E \# a t=287>$. Atentem no vídeo para as seguidas manifestações contrárias à rede Globo, expressas dentre outras formas pelo refrão "O povo não é bobo, abaixo a rede Globo". 
E conclui, descaradamente:

-... Estamos vivendo um momento histórico lindo e novo... Esses jovens terão nos dado uma lição. Democracia já temos. Agora temos que formar uma república!

Expressando entendimento por mim compartilhado, contrário aos acima desenvolvidos, Saul Leblon, em editorial intitulado "Bola Rolando: Democracia X Mercado na América Latina", do boletim eletrônico - Carta Maior"'13, afirma - após pergunta retórica sobre o possível esgotamento da viabilidade de uma construção negociada da democracia social na AL, nos marcos da economia de mercado - que "A tentativa de construir uma democracia social na América Latina - a região mais desigual do planeta - tornou-se um espinho na garganta do jogral conservador. Equiparar a igualdade de direitos civis ao seu equivalente no campo econômico, significa levar a sério a democracia como o regime intrinsecamente dotado de meios para dilatar seus próprios fins”.

Em síntese, afirma:

"significa não pedir autorização ao dinheiro para transformar carências em direitos e dívidas históricas em lei. A última palavra dependeria da competência progressista para adensar força e consentimento majoritário aos seus projetos e plataformas".

E continua:

"A experiência histórica latino-americana está coalhada de interpretações controversas acerca desse mandato atrelado à formação das grandes maiorias. A coleção de golpes de Estado espetados nas entranhas de seus distintos países sugere que o princípio que equipara cada cidadão a um voto promete mais do que as elites locais estão dispostas a conceder”.

E diz de forma peremptória:

"O mercado fala por elas. Mercados e seu aparato ideológico dedicam-se diuturnamente à tarefa de capturar o imaginário social, algemar o Estado

13 Boletimeletrônico-Carta Maior-, Editorial de 26 fev. 2014. Disponível em:<http:// www.cartamaior.com.br/?/Editorial/Bola-rolando-Democracia-x-Mercados-na-AL/30349>. 
e amordaçar instituições para vestir o enforcador no pescoço da democracia, apartando-a dos interesses majoritáriosda sociedade. Movimentos progressistas, ao contrário, empenham-se na interminável repactuação de maiorias para submeter a lógica do dinheiro ao imperativo da democracia social, no passo seguinte da luta pelo desenvolvimento".

"Toda assepsia que o neoliberalismo se empenha em promover na profundidade e abrangência da ação pública e estatal persegue esse objetivo de emascular as ferramentas da democracia. Alto-falantes da emissão conservadora martelam diuturnamente a superioridade dos livres mercados para alocar recursos ao menor custo e com maior eficiência. O oposto é esgrimido como um desastre inelutável”.

À Democracia, diz então, caberia "sancionar o livre arbítrio de uma economía desregulada, para que a sua 'imanente racionalidade' pudesse se traduzir em geração de riqueza e ganhos de eficiencia”.

E aí fala explicitamente do Brasil:

“O que os tucanos ${ }^{14}$ ecoaram na efeméride dos 20 anos do Plano Real, é que a coalizão demotucana ${ }^{15}$ preparou a economia do país para isso ao domar a hiperinflação nos anos 90, privatizar instrumentos importantes da ação pública e estreitar a inserção internacional do país (via endividamento interno e externo, sem dúvida). O ciclo de governos do PT teria desvirtuado esse saudável legado ao restaurar critérios, gastos e ferramentas que devolveram à esfera pública - e às urnas da qual esta depende - o poder de disputar o comando do desenvolvimento com os mercados".

E conclui seu raciocínio: "Esse jogo está sendo jogado. Se o placar final vai dizer que, de fato, esgotou a viabilidade de uma construção negociada da democracia social na América Latina nos marcos da economia de mercado, é impossível prever" ${ }^{16}$

14 “Tucanos”, pássaros da fauna brasileira, é o símbolo do PSDB - Partido Social Democrata Brasileiro - sendo seus filiados assim chamados.

15 Está se referindo à aliança do Partido Democrata, situado à direita do campo político, com o PSDB.

16 Ao final do editorial, Saul Leblon anexa carta assinada pelo ex-presidente LULA intitulada - Porque o Brasil é o país das Oportunidades-, na qual traz dados reforçadores da pertinência da política econômica adotada pelo governo petista a partir de 2003 . 


\section{Megaeventos esportivos e seus legados}

$7,1 \%$. Esta é a taxa média de crescimento anual do setor esportivo no Brasil no período de 2007 a 2011, conforme levantamento efetuado pela Pluri Consultoria $^{17}$. No mesmo período o Produto Interno Bruto brasileiro apontou um crescimento médio de $4,2 \%$. Os investimentos no setor propiciaram, em 2011, a taxa de representação de 1,6\% do setor esportivo no PIB brasileiro, aproximadamente R $\$ 67$ bilhões, algo ao redor de 38,5 milhões de dólares no câmbio da época, pouco para o governo brasileiro que segundo a Revista Fórum ${ }^{18}$, esperava algo entorno de 1,8\% do PIB nacional. Uma coisa parece ser consensual: a taxa anual do crescimento do PIB esportivo continuará superando a do PIB brasileiro, notadamente em tempos de megaeventos esportivos...

Sim... Os dados acima reforçam nossa defesa da tese de que os Megaeventos esportivos são menos resultado da articulação do campo esportivo brasileiro e manifestação de sua força e mais a conjugação de interesses de Governo centrados em uma determinada compreensão de desenvolvimento e de inserção protagônica do país no cenário mundial.

Para melhor compreendermos o acima dito se faz necessário breve incursão à política esportiva brasileira. Para tanto nos valemos de excerto de artigo de livro por nós publicado e aqui já mencionado. Nele iniciamos afirmando que -... A presença do Estado brasileiro nas questões do esporte é incontestável, atestada na própria história da organização social e política do país, notadamente aquela construída a partir da segunda década do século passado, quando o Brasil deixava para trás o modelo econômico agrário de natureza comercial- exportador e se organizava dentro do mote da industrialização, pautada pelo modo de produção capitalista'.

Depois de aprofundarmos nossa compreensão acerca dos documentos legais configuradores de uma primeira perspectiva de intervenção estatal na

17 Disponível em: <http://www.pluriconsultoria.com.br/uploads/relatorios/pib\%20esporte.pdf>

18 Disponívelem:<http://revistaforum.com.br/digital/131/imagine-depois-da-copa>.Vertambém: $<$ http://oglobo.globo.com/economia/pib-do-esporte-cresce-mais-do-que-do-país-5028799>;

$<$ http://www.fiesp.com.br/noticias/pratica-esportiva-representa-19-do-pib-brasileiroafirma-professor-da-fgv-durante-reuniao-da-comissao-da-cadeia-produtiva-do-desporto-da-fiesp/> 
política esportiva brasileira ${ }^{19}$, passamos a nos reportar a outro momento do ordenamento legal esportivo:

'O conjunto legal até aqui referido - reforçador da oligarquização da organização esportiva - foi substituído por outro, descompassado da Constituição brasileira de 05 de outubro de 1988 e formatado sobre forte influência dos referenciais neoliberais de Estado e Governo que passaram a vigorar em nosso meio, ao arrepio da Constituição Cidadã'.

'Constituído pela Lei Zico (Lei 8672/93 e Decreto 981/93) e pela Lei Pelé (Lei 9615/98 e Decreto 2574/98), esse outro conjunto deu margem ao descrito por Meily Assbú Linhales ${ }^{20}$ como um processo de mudança dirigido fundamentalmente pelo confronto entre os interesses liberalizantes - que buscavam autonomia de mercado para o esporte - e os interesses conservadores, que entendiam essa liberalização como uma ameaça ao poder constituído oligarquicamente'.

'O embate entre liberalizantes e conservadores foi responsável pelo surgimento da autonomia e da pluralidade como elementos de mudança. Contraditoriamente, mesclavam-se aos traços deixados pela conservação de antigas práticas. Tal linha de reflexão - ainda de acordo Linhales — nos conduziu a um quadro onde, em nenhuma das duas direções se consolidaram alternativas que vissem o Esporte como uma necessidade e/ou direito social, e tampouco o Estado como mediador e ponto de equilíbrio entre os interesses antagônicos existentes no setor esportivo'.

E então nos reportamos ao século XXI:

'A chegada do PT ao Governo Federal, mesmo que limitada pelas alianças ao centro e dele, à direita, acenou para a possibilidade de assunção do postulado contra-hegemônico da indicação de parâmetros para que a democratização do Esporte (e da libertação do lazer de seu jugo) pudesse ocorrer e ser usufruída por todo o conjunto da população brasileira'.

19 Essa intervenção sedimentou-se ao longo dos 34 anos em que o Decreto-lei 3.199/41 regeu a vida esportiva brasileira, vindo a consolidar-se em outro momento de regime de exceção - desta feita de natureza civil-militar - através da Lei 6.251 de 1975 regulamentada, dois anos mais tarde, pelo Decreto 80.228.

20 Conforme Meily Assbú Linhales. Dissertação de Mestrado “A trajetória política do esporte no Brasil: interesses envolvidos, setores excluídos”. Programa de Pós-Graduação em Ciência Política da Universidade Federal de Minas Gerais, UFMG, 1996. 
'Materializar-se-ia assim, o objetivo de sinalizar para a inversão da lógica da presença do Estado no campo esportivo, atribuindo-lhe prioritariamente caráter subsidiador, contudo, de outro sentido que não aquele reforçador do modelo concentrador representado graficamente por uma pirâmide trazendo, em seu vértice, o esporte de alto rendimento e, em sua base e centro, respectivamente, o esporte de massa e o esporte estudantil subordinados aos objetivos do de Cima'.

'Esse quadro — visualizado como possibilidade histórica — não se traduziu em realidade histórica, frustrando a expectativa de muitos e empurrando para frente a materialização do que ainda permanece no universo da utopia'.

\section{O Esporte na perspectiva da cidade Empresarial}

Os interesses do segmento conservador do campo esportivo, por si só configurado em facetas conservadoras, retrógradas e reacionárias, aliaram-se a uma concepção de desenvolvimento urbano configurativo da cidade de exceção, movida pela lógica empresarial fomentadora do batizado por Carlos Vainer de Democracia Direta do Capital refratária à intermediação dos movimentos sociais e dos partidos políticos e simpática à ligação direta governo/empresariado, quadro esse propício à materialização das condições objetivas para a realização dos megaeventos esportivos ${ }^{21}$.

Não obstante a ojeriza da lógica acima à presença junto a eles dos movimentos

sociais e partidos políticos, os primeiros - mais do que os segundos -, movidos por interesses legítimos afetos ao universo da cidadania ainda que circunscrita à dimensão da emancipação política e não ao da emancipação humana, não deixaram de se manifestar de forma articulada, alcançando fazer soar as vozes dos que - sem poder político e econômico e, em consequência, sem acesso à grande mídia, por sua vez interessada nos dividendos financeiros a advir

21 Sugerimos neste particular acompanhar a fala do professor Carlos Vainer por ocasião de sua participação no programa da ESPN - Brasil chamado - Juca Entrevista-, de um renomado jornalista esportivo brasileiro, Juca Kfouri. Disponível em: <http://www. youtube.com/watch?v=ZKDRaZXajIg>. 
com a realização dos megaeventos - recebiam como legado social políticas centradas no conceito de Gentrificação $O^{22}$.

O estudo desses movimentos sociais foi objeto da dissertação de mestrado desenvolvida por Juliana Cristina Barandão intitulada " $A$ Copa FIFA 2014 no Brasil para além da Política Esportiva: Estudo do dissenso entre os interesses da 'Cidade mpresarial' e os dos citadinos, através da análise da ação dos movimentos sociais" ${ }^{23}$. Fiquemos com seu resumo:

"O cenário da realização de megaeventos esportivos em solo brasileiro, desde os Jogos Pan-Americanos de 2007 e a Copa das Confederações 2013, até a Copa FIFA 2014 e as Olimpíadas de Verão em 2016, evidencia a emergência de um modelo de planejamento de cidade pautado na racionalidade econômica e na gestão empresarial do espaço urbano. A lógica mercantil da organização dos megaeventos e a sua utilização como dispositivo econômico do capital de criação de novos nichos e demandas de serviços para conter a crise estrutural do capitalismo, tende a impactar positivamente para aqueles que detêm capital financeiro - aos empresários dos setores da construção civil e do setor hoteleiro, por exemplo. Já o impacto negativo fica quase que exclusivamente debitado na conta dos setores desfavorecidos da população. Isso porque a organização desses eventos se vale da lógica da Gentrificação de setores da cidade, vale dizer, a incumbência de organizar o evento carrega em si a justificativa ideal para o "saneamento socioeconómico" do local, dele decorrendo a remoção desses espaços dos segmentos sociais ali presentes muitas vezes remanescentes de ocupações consideradas "ilegais”. Também segmentos da população, ali estabelecidos legalmente, são afetados pela lógica de "cidade de exceção" configurada. Esses citadinos, organizados em entidades e movimentos sociais, constroem mecanismos de resistência na defesa de seus diretos. Muitos são os relatos de violações dos direitos da população local das cidades sedes de eventos esportivos de grande porte, como a Copa/FIFA se configura, e muitos são os grupos/movimentos sociais

22 Trata-se de conceito referente ao processo de saneamento econômico de regiões urbanas através da remoção desses espaços dos segmentos sociais desfavorecidos, muitas das vezes remanescentes de ocupações ilegais e/ou tidas como tais pelos poderes constituídos.

23 A referida Dissertação foi desenvolvida junto ao Programa de Pós-Graduação em Educação Física da Universidade Estadual de Campinas, Unicamp, e submetida à defesa pública em fevereiro deste ano de 2014. 
articulados a partir da temática desse evento debatendo, questionando e colocando em evidência a violação dos direitos sociais dessa população. Foi essa organização, suas características e ações, o objeto de nosso estudo. Assim, o objetivo deste trabalho consistiu no mapeamento dos movimentos sociais que fizeram ou ainda fazem o embate político contra aqueles responsáveis pelos impactos contrários aos interesses dos setores sociais desprivilegiados, discutindo os aspectos políticos, econômicos e principalmente sociais decorrentes da realização da Copa do Mundo de 2014 nas 12 cidades-sedes escolhidas”.

Articulação Nacional dos Comitês Populares da Copa-ANCOP - é o nome do ente organizador dos distintos comitês dispersos pelo Brasil afora, notadamente nas

doze cidades-sede da Copa. Foi ele o responsável pela elaboração do dossiê dos megaeventos esportivos, documento síntese do legado que eles estão deixando aos setores populares brasileiros, o qual segue o roteiro anunciado ${ }^{24}$.

Por sua vez, no bojo das manifestações de junho de 2013 e as realizadas por ocasião da Copa das Confederações, além daquelas que se sucederam de lá para cá, vamos encontrar bandeiras balizadas pelo entendimento de que os recursos destinados a eles, megaeventos, poderiam ser mais bem utilizados se voltados para outros campos das políticas públicas. A partir dessa compreensão vimos expandir país afora o lema — professor vale mais que Neymar-, numa clara alusão às condições de trabalho que afetam os profissionais da educação ${ }^{25}$. A dimensão política de tais mobilizações se sobressai menos pela sua pertinência - de fato as condições da Educação Pública brasileira são merecedoras de atenção especial - e mais pela ausência de cotejo com dados insofismáveis, como os trazidos pelo professor do Instituto de Economia da

\section{O referido dossiê está disponível em}

http://comitepopulario.files.wordpress.com/2013/05/dossie_comitepopularcoparj_2013. pdf Além dele sugerimos o vídeo sob o tema —Cidades rebeldes-, no qual os professores Mário Iasi e Carlos Vainer, por nós já mencionados, refletem sobre a resistência entabulada pela população atingida pelos procedimentosorganizativos da Copa FIFA 2014, disponível em

http://www.youtube.com/watch?v=7AUGExvwtsY\&list=TLL7FZxVA_uf- IKRBcg_Mj1c2rfVTHJbhV

25 Foi o que assistimos por ocasião da Copa das Confederações, conforme nos mostra o vídeo da TV UOL de 01 de julho de 2007, passível de ser visto no endereço. http://tvuol.uol.com. $\mathrm{br} /$ assistir.htm? \&tagIds=74107\&time=all\&orderBy=mais- recentes\&edFilter=editorial\&video =professor-vale-mais-que-neymar-grita-protesto-no-maracana-04028C1B326CDCA94326 
Unicamp, Marcelo Proni. Em artigo publicado no jornal Folha de São Paulo, ele esclarece que - o investimento total em infraestrutura na preparação para a Copa equivale a cerca de $5 \%$ do valor dos investimentos do PAC (Programa de Aceleração do Crescimento), ao passo que os empréstimos do BNDES concedidos para a construção e reforma das arenas corresponde a menos de $3 \%$ do montante que essa instituição financeira empresta anualmente ${ }^{26}$.

Como que referendando os dados do professor da Unicamp, Felipe Rodrigues nos traz matéria a nosso ver elucidativa ao estabelecer o cotejo entre o orçamento da União e os investimentos públicos para a Copa, além de não descurar da legitimidade das mobilizações sociais, todavia não as tratando de forma monolítica ao sinalizar os distintos motivos que as originam.

Vamos a ela:

"Orçamento da União e os investimentos para a Copa"

"Tem dinheiro pra Copa, mas não tem dinheiro para Saúde e Educação, né? Vamos aos números:”

Orçamento da União:

“R\$ 79.331 bilhões para a Saúde só em 2013".

"R\$38.093 bilhões para a Educação só em 2013".

"R $\$ 26.621$ bilhões para a Copa desde a escolha do Brasil como sede até a realização do evento em 2014. Média, portanto, de R 4 bilhões por ano".

"Desses $\mathrm{R} \$ 26$ bi da Copa, a maior rubrica, $\mathrm{R} \$ 8,6$ bilhões é destinada a projeto de mobilidade urbana. A razão dos protestos em São Paulo durante essa semana não é exatamente a necessidade de investimentos em uma nova política de mobilidade urbana nas grandes cidades brasileiras?”

"Outros R \$ 6,8 bi são para melhorar os aeroportos das cidades-sedes e há ainda investimentos em segurança, portos, telecomunicações e turismo. Investimentos que o Brasil precisa e que ficarão como benefício para a população mesmo depois da Copa".

26 A Copa é bom negócio para o Brasil? não-. Folha de São Paulo, São Paulo, 7 dez. 2013. Caderno Opinião, Seção Tendências \& Debates. Disponível em:

<http://www1.folha.uol.com.br/opiniao/2013/12/1382181-marcelo-weishaupt-proni-bompara-quem.shtml>. 
"Há, contudo, R $\$ 7$ bilhões destinados a construção e reformas de estádios (menos de $10 \%$ o orçamento da Saúde em um único ano). Vale a pena gastar esse recurso para sediar um evento como a Copa do Mundo? Não há retornos econômicos, fiscais, geração de emprego e aumento do turismo internacional? Não sei, mas esse é o verdadeiro debate".

"Posso discordar da opinião dos que se manifestam contra a realização da Copa no Brasil, mas estes lutam por uma causa nobre e exercem um direito irrevogável num sistema democrático. Os que incitaram a vaia a Dilma dentro do estádio tem horror a eles, ali estava a elite brasiliense que chama manifestante de vândalo, gente cuja revolta é vinte centavos a mais no preço do combustível para colocar no seu carro importado, gente que odeia ter que pagar imposto para "dar bolsa-esmola para vagabundo". O maior erro de Dilma, e é isso que estavam dizendo aqueles que estavam do lado de fora do estádio, é ter aceitado a Copa no Brasil tão elitista como em qualquer outro lugar do mundo".

"Dizer que a Copa é a razão dos problemas do país, que não tem dinheiro para investir em outras coisas mais importantes, que a vaia é resultado de Dilma ter fechado os olhos para os problemas do país é só repetir o discurso de gente mal intencionada que quer aproveitar movimentos populares justos e necessários para levar ao poder quem trata o povo com a mesma truculência da PM de Alckmin." ${ }^{27}$

As condições necessárias para identificarmos no nosso modelo societário e na nossa ainda tênue — porque recente- democracia, os motivos fundantes para a resistência de parcela significativa de nossa sociedade à realização dos megaeventos esportivos em nosso país parecem estar presentes. ${ }^{28}$

A ausência de mecanismos possibilitadores da participação popular nas instâncias decisórias das ações governamentais, responsável pela consequente ausência de controle social dessas mesmas ações de governo,

27 Disponível na página virtual de respeitado jornalista de economia, Luiz Nassif,

http://www.advivo.com.br/blog/luisnassif/orcamento-da-uniao-e-os-investimentos-para-a-copa

Alckmin é governador do Estado de são Paulo. Por sua vez, a página Portal da Transparência, de responsabilidade do Governo Federal, traz dados abonadores da reflexão desenvolvida por Felipe. Disponível em http://www.portaltransparencia.gov.br/copa2014/empreendimentos/ investimentos.seam?menu=2\&assun to=tema

28 A esse respeito acessem - Aprovação à realização da Copa é a menor em 5 anos http://www1.folha.uol.com.br/cotidiano/2014/02/1416810-aprovacao-a-realizacao-da-copae-a-menor- em-5-anos.shtml 
alavanca o sentimento nacional de descrédito em nossas instituições políticas, do executivo ao judiciário, passando pelo legislativo, percebendo-as todas eivadas de práticas corruptas como nunca em nossa história, não permitindo a percepção de que hoje, diferentemente de um passado recente, práticas nocivas ao tecido social são cada vez mais passíveis de denúncia e punição, expressando um movimento radicalmente contrário àquele perceptível no âmbito do senso comum ${ }^{29}$. Por mais que almejemos - e quanto almejamos! - a superação do ordenamento societário sob o qual se estrutura a sociedade brasileira, entendemos que muito ainda podemos e precisamos fazer dentro deste instituído.

Se isso vale para as questões maiores que nos afetam, vale também para aquelas pertinentes ao campo esportivo. A democratização das entidades de administração e prática esportivas urge ser realizada de modo a eliminarse de uma vez por todas a configuração delas como verdadeiros feudos nas mãos de senhores feudais modernos que se eternizam no poder, fazendo uso privado da estrutura esportiva nacional que deveria estar a serviço de efetivar a máxima constitucional de termos o Esporte como direito social ${ }^{30}$.

Os megaeventos esportivos aqui já estão e com eles também chegaram a possibilidade histórica de dizermos um basta à concepção de cidade empresarial aqui explicitada, e encararmos a necessidade de construção de política pública de esporte signatária de um sistema nacional de esporte que, a partir de

29 Sobre o tema da participação popular na configuração da política pública de esporte, indicamos a Dissertação de Mestrado de Lia Polegato Castelan intitulada "As Conferências Nacionais do Esporte na configuração da política esportiva e de lazer no Governo LULA (2003-2010) - elaborada junto ao Programa de Pós-Graduação em Educação Física da Unicamp e submetida à defesa pública no ano de 2010. De forma indireta e não explorada neste trabalho, indicamos também a Dissertação de Mestrado de Juliane Cristine Correia, denominada "O setor privado sem fins lucrativos e as políticas de esporte e lazer (2008-2011)", elaborada junto ao Programa de Pós-Graduação em Educação Física da Unicamp e submetida à defesa pública no ano de 2012.

30 Tratamos do tema em crônica intitulada "Os Senhores dos Anéis" (p. 119-121) presente no livro, aqui já citado, -Educação Física, Esporte e Lazer: Reflexões nada aleatórias-. Por sua vez, em 15 out. 2013 foi sancionada a Lei $\mathrm{n}^{\circ} 12.868$ que no seu artigo 19, inciso I, limita o tempo de mandato dos dirigentes das entidades de administração do Esporte para o período de 4 anos com direito a uma única recondução ao cargo. Recomendamos ainda o acesso ao blog do professor Fernando Mascarenhas, um dos estudiosos que vem priorizando em seus aportes o tema dos megaeventos esportivos, enfatizando o impacto dos mesmos no âmbito da produção de conhecimento na área acadêmica Educação Física. Disponível em <http://blogdomasca.blogspot.com.br/s 
seu reconhecimento como patrimônio cultural da humanidade, deite por terra as iniciativas de tratá-lo como mera mercadoria passível de negócio e negocia$\operatorname{tas}^{31}$, colocando-o definitivamente ao alcance de todos nós.

Assim, aos que esbravejam não vai ter $\operatorname{Copa}^{32}$, devemos responder sim, teremos... Não a que desejávamos, voltada a um povo que têm no futebol a prática social identificadora de sua cultura corporal esportiva. Não aquela de índole popular que um dia fez com que um de nossos maiores dramaturgos ${ }^{33}$ batizasse nosso país de pátria das chuteiras...

De fato é outra Copa que se avizinha, elitizada, macdonaldizada pelo Padrão FIFA, padrão esse que exigimos para nossas vidas, e que com a persistência de nossa vontade política aliada a condições objetivas ainda não presentes, um dia viabilizaremos ${ }^{34}$.

\section{Referências}

Anjos, A. B. Imagine depois da copa: protestos contra o mundial trazem a reflexão sobre qual será de fato o legado do evento para o Brasil. Revista Forum. Disponível em <http://revistaforum.com.br/digital/131/imagine-depois-da-copa $>$.

31 Recomendamos o acesso da matéria presente na página abaixo que documenta a relação entre Estado e empresas no contexto dos grandes eventos e empreendimentos no Rio de Janeiro. Disponível em: <www.proprietariosdobrasil.org.br/wiki/index. php?title=Donos_Do_Rio>

32 Tendo redes sociais como canal de mobilização, várias chamadas para atos de sabotagem à Copa ganham destaque, como a passível de ser vista na notícia divulgada no endereço:

$<$ http://www1.folha.uol.com.br/fsp/cotidiano/153087-protestos-contra-mundial-planejam-ate-apagao-em- jogo.shtml>

Comentando o movimento Não vai ter Copa, o jornalista esportivo Juca Kfouri, em seu blog, traz análise ao mesmo tempo simples e contundente. Leiam no endereço: $<$ http://blogdojuca.uol.com.br/2014/01/vai- ter-copa/s

33 Estamos nos referindo a Nelson Rodrigues.

34 Vale a pena aqui ouvirmos a música —Desculpe Neymar-, de Edu Krieger, cuja letra se revela extremamente perspicaz ao expressar sentimento presente em muitos brasileiros. Acesso: http://www.youtube.com/watch?v=iwL3TxSeDmA 
Articulação nacional dos comitês populares da copa. Megaeventos e violações dos direitos humanos no Rio de Janeiro: dossiê popular da copa. Disponível em <http://comitepopulario.files.wordpress.com/2013/05/dossie_comitepopularcoparj_2013.pdf>.

Athayde, P. F. A. (2014). O ornitorrinco de chuteiras: determinantes econômicos da política de esporte do governo LULA e suas implicações sociais. 2014. Tese (Doutorado em Política Social) - Universidade de Brasília, Brasília, DF.

Barandão, J. C. (2014). A Copa FIFA 2014 no Brasil para além da política esportiva: estudo do dissenso entre os interesses da "cidade empresarial" e as dos citadinos, através da análise da ação dos movimentos sociais. Dissertação (Mestrado em Educação Física) - Faculdade de Educação Física, Universidade Estadual de Campinas.

Boito Júnior, A. As bases políticas do neodesenvolvimentismo. Disponível em <http:// eesp.fgv.br/sites/eesp.fgv.br/files/file/Painel\%203\%20-\%20Novo\%20Desenv\%20 BR\%20\%20Boito\%2020Bases\%20Pol\%20Neodesenv\%20-\%20PAPER.pdf>.

Boron, A. A. Brasil: um novo ciclo delutas populares?. Disponível em http://www. atilioboron.com.ar/2013/06/brasil-un-nuevo-ciclo-de-luchas.html.

Brasil. (2014). Controladoria Geral da União. Portal da Transparência. Disponível em http://www.portaltransparencia.gov.br/copa2014/empreendimentos/investimentos.seam? menu=2\&assunto=tema.

Camargo, T. Prática esportiva representa 19\% do PIB brasileiro, afirma professor da FGV durante reunião da comissão da cadeia produtiva do desporto da FIESP. Agência Indusnet FIESP. Disponível em http://www.fiesp.com.br/noticias/praticaesportiva- representa-19-do-pib-brasileiro-afirma-professor-da-fgv-durante-reuniaoda-comissao-da-cadeia-produtiva-do-desporto-da-fiesp/.

Carvalho, C. S. \& Rossbach, A. (2010). Estatuto da cidade: comentado. São Paulo: Ministério das Cidades: Aliança das Cidades. Disponível em: <http://www.ifrc.org/ docs/idr1/947PT.pdf>.

Castellani, L. (2013). Educação Física, esporte e lazer: reflexões nada aleatórias. Campinas: Autores Associados. (Coleção Polêmicas de Nosso Tempo, nº 105, 2013).

Castelan, L. P. (2010). As Conferências nacionais do esporte na configuração da política esportiva e de lazer no governo LULA (2003-2010). Dissertação (Mestrado em Educação Física) - Faculdade de Educação Física, Universidade Estadual de Campinas. 
Correia, J. C. A. (2012). O setor privado sem fins lucrativos e as políticas de esporte e lazer (2008 - 2011). Dissertação (Mestrado em Educação Física) - Faculdade de Educação Física, Universidade Estadual de Campinas, Campinas.

Iasi, M. \& Vainer, C. Cidades rebeldes. Disponível em: http://www.youtube.com/wa tch?v=7AUGExvwtsY\&list=TLL7FZxVA_uf- $1 \mathrm{KRBcg}$ _Mj1c2rfVTHJbhV>.

Iasi, M. (2013). Pode ser a gota d'água: enfrentar a direita avançando a luta socialista. Disponível em: <http://blogdaboitempo.com.br/2013/06/26pode-ser-a-gotadagua-enfrentar-a-direita-avancando-a-luta-socialista/>.

Jabor, A. (2013). Sobre as manifestações sociais de junho de 2013. Disponível em:

$<$ http://www.youtube.com/watch?feature=player_embedded \&v=aS7LmKld_ $\mathrm{mE} \# \mathrm{at}=287>$.

Kfouri, J. Juca entrevista Carlos Vainer. Disponível em <http://www.youtube.com/ watch?v=ZKDRaZXajIg>.

Kfouri, J. Vai ter copa. Disponível em <http://blogdojuca.uol.com.br/2014/01/vaiter-copa/>.

Krieger, E. Desculpe Neymar. Disponível em <http://www.youtube.com/watch?v= iwL3TxSeDmA>.

Leblon, S. (2014). Bola rolando: democracia x mercado na américa latina-. Boletim Eletrônico “Carta Maior”. Disponível em:

$<$ http://www.cartamaior.com.br/?/Editorial/Bola-rolando-Democracia-x-Mercadosna- AL/30349>.

Linhales, M. A. (1996). A trajetória política do esporte no Brasil: interesses envolvidos, setores excluídos. Dissertação (Mestrado) - Universidade Federal de Belo Horizonte, Belo Horizonte.

Maisonnave, F. Aprovação à realização da copa é a menor em 5 anos. Disponível em: <http://www1.folha.uol.com.br/cotidiano/2014/02/1416810-aprovacao-a-realizacaoda-copa-e- a-menor-em-5-anos.shtml>.

Mascarenhas, F. Blog do Fernando Mascarenhas: falando de esporte e política. Disponível em < http://blogdomasca.blogspot.com.br/>.

Pluri consultoria. O PIB esportivo brasileiro. Disponível em <http://www.pluriconsultoria.com.br/uploads/relatorios/pib\%20esporte.pdf>. 
Prado, M. C. R. M. (2014). Renda, de volta a 1964. Valor Econômico. Disponível em www.valor.com.br.

Proni, M. A. (2013). Copa é bom negócio para o Brasil? não. Folha de São Paulo, São Paulo. Caderno Opinião, seção Tendências \& Debates Disponível em http:// www1.folha.uol.com.br/opiniao/2013/12/1382181-marcelo-weishaupt-proni-bompara-quem.shtml.

Protestos contra mundial planejam até apagão em jogo. (2014). Folha de São Paulo, São Paulo. Disponível em http://www1.folha.uol.com.br/fsp/cotidiano/153087protestos-contra-mundial-planejam-ate- apagao-em-jogo.shtml.

Spitz, C. PIB do esporte cresce mais do que o do país. Disponível em http://oglobo. globo.com/economia/pib-do-esporte-cresce-mais-do-que-do-país-5028799.

TV UOL. Professor vale mais que Neymar, grita protesto no Maracanã. Disponível em http://tvuol.uol.com.br/assistir.htm? \& tagIds=74107\& time=all\&orderBy=ma is-recentes \&edFilter=editorial\&video=professor-vale-mais-que-neymar-gritaprotesto-no-maracana-04028C1B326CDCA94326.

Vainer, C. (2011). Cidade de exceção: reflexões a partir do Rio de Janeiro. In: ENCONTRO NACIONAL DA ANPUR. Disponível em http://www.opp.ufc.br/urbano04.pdf.

WIKI INDEX. Proprietários do Brasil, donos do Rio. Disponível em http://www. proprietariosdobrasil.org.br/wiki/index.php?title=Donos_Do_Rio 